\title{
PRESCRIBING TRENDS IN A TEACHING HOSPITAL IN NEPAL
}

\author{
Ghosh R*, Neogi J N, Srivastava B S*, Sen P*
}

\section{ABSTRACT}

Prescriptions of the patients at the time of admission to the college of Medical Sciences (CMS), Bharatpur, Nepal were collected for a period of 6 months to study the prescribing pattern in a teaching hospital. The prescriptions were subjected to critical evaluation using WHO basic drug use indicators. The average number of drugs per prescription was 4.34. Percentage of drugs prescribed by generic name and percentage of fixed drug combinations (FDCs) were 22.57 and 17.49 respectively. The percentage of prescriptions containing antimicrobials $(\mathbf{7 2 . 0 5 \%})$ and injections $(66.66 \%)$ were relatively more in our study. Percentage of drugs prescribed from the WHO essential drug list and the Nepal essential drug list were $41.76 \%$ and $38.20 \%$ respectively. The most commonly used group of drugs were antimicrobials(32.27\%), followed by analgesics $(11.85 \%)$ and drugs for acid-peptic-disorders(10.72\%). The present drug utilization study is to give feedbacks to the prescribers, so as to create awareness about the rational use of drugs.

\section{INTRODUCTION}

The irrational and inappropriate use of drugs is a well documented universal problem and is a major concern for both in developed and developing countries, as has been recognized by the World Health Organization (WHO) ${ }^{1}$. Bad prescribing habits lead to ineffective and unsafe treatment, exacerbation or prolongation of illness, and higher costs ${ }^{2}$. "It is such a waste of resources, which a developing country like ours can illafford" ${ }^{\prime \prime}$.The common irrational prescribing patterns include polypharmacy, the use of drugs of poor therapeutic value, the use of drugs that are not related to the diagnosis, the unnecessary use of potent drugs, the inappropriate use of antimicrobials and use of unnecessary expensive drugs. Prescriptions and drug utilization patterns need to be evaluated from time to time so as to increase the therapeutic efficacy, decrease the adverse effects and to provide feedback to the prescribers to create awareness towards rational use of drugs $s^{4,5,6}$. Keeping all these facts in consideration, the present study has been planned to define the pattern of drug use in a tertiary care hospital in Nepal.

\section{MATERIALS AND METHODS}

Prescriptions were collected during the period of January 2003 to June 2003 from the admitted patients in different departments of College of Medical Sciences (CMS), Bharatpur, Nepal. The prescriptions at the time of admission to the hospital were included into the study. The drugs prescribed during follow-up or at the time of discharge were not taken into consideration. All prescriptions were entered into a specially designed proforma as given in Kathmandu-University undergraduate curriculum ${ }^{7}$ to record the required information of the prescriptions. Each prescription was subjected to critical evaluation using WHO guidelines as described in accordance with "how to investigate drug use in health facilities?"8. WHO model list of essential drugs $(2002)^{9}$ and National list of essential drugs, Nepal (2002) ${ }^{10}$ were used to find out the percentage of drugs and fixed-dose drug combinations from essential drug lists. The following prescribing indicators were assessed to evaluate the drug-prescribing pattern in this tertiary health care center in Nepal.

* College of Medical Sciences, Bharatpur, Chitwan, Nepal.

Address for correspondence : Dr. Ranjib Ghosh

College of Medical Sciences, Bharatpur, Nepal

Email: ghoshranjib@rediffmail.com 
1. Average number of drugs per prescription.

2. Percentage of drugs prescribed by generic name.

3. Percentage of prescriptions with antimicrobial(s) prescribed.

4. Percentage of prescriptions with injection(s) prescribed.

5. Percentage of drugs prescribed from essential drug list.

In addition to the above WHO prescribing indicators, percentage of fixed drug combinations from essential drug list and percentage of different groups of drugs prescribed were also analyzed to find out the rational use of fixed dose drug combinations and utilization pattern of different groups of drugs in this teaching hospital.

\section{RESULTS}

Two hundred and four (204) prescriptions were evaluated from the admitted patients of CMS, Bharatpur, Nepal. The average number of drugs per prescription was 4.34. The different prescribing indicators and distribution of different categories of drugs prescribed are shown in table-I and table-II respectively.

\section{The study revealed that:}

1. Average number of drugs per prescription was 4.34 .

2. Percentage of drugs prescribed by generic name was 22.57 .

3. Drugs prescribed from essential drug lists of WHO and Nepal were $41.76 \%$ and $38.20 \%$ respectively.

4. Percentage of fixed dose-drug combinations was 17.49 and only $20 \%$ and $6.40 \%$ of them were approved by WHO and Nepal essential drug lists respectively.

5. Among the different categories of drugs, antimicrobials $(32.27 \%)$ were the most commonly prescribed agents, followed by analgesics $(11.85 \%)$ and drugs for acid-peptic disorders $(10.72 \%)$.

Table I : Analysis of Prescriptions from College of Medical Sciences, Bharatpur, Nepal

\section{Prescribing Indicators}

\begin{tabular}{lc} 
Total number of prescriptions analyzed & 204 \\
Total number of medicines prescribed & 886 \\
\hline Average number of drugs/prescription & 4.34 \\
Percentage prescribed as generic name & 22.57 \\
\hline Percentage of prescriptions with antimicrobial(s) & 72.05 \\
Percentage of prescriptions with injection(s) & 66.66 \\
Percentage of drugs from WHO essential drug list & 41.76 \\
\hline Percentage of drugs from Nepal essential drug list & 38.20 \\
Percentage of fixed-dose drug combinations (FDCs) & 17.49 \\
\hline Percentage of FDCs approved by WHO essential drug list & 20 \\
\hline Percentage of FDCs approved by Nepal essential drug list & 6.40
\end{tabular}

Table II : Distribution of Different Categories of Drugs in the Prescriptions Collected from CMS, Bharatpur, Nepal

\begin{tabular}{l|c|c}
\hline \multicolumn{1}{c|}{ Categories of Drugs } & Total & Percentage \\
Antimicrobials & 286 & 32.27 \\
Analgesics & 105 & 11.85 \\
\hline Drugs for acid-peptic disorders & 95 & 10.72 \\
Drugs for cardiovascular disorders & 74 & 8.35 \\
Multivitamin preparations & 57 & 6.43 \\
\hline Drugs for psychiatric \& neurological disorders & 42 & 4.74 \\
Topical formulations & 32 & 3.61 \\
\hline Hormones & 31 & 3.49 \\
\hline Cough and cold remedies & 16 & 1.80 \\
Antihistaminics & 16 & 1.80 \\
\hline Antioxidants & 15 & 1.69 \\
\hline Prokinetic and antiemetics & 12 & 1.35 \\
Laxatives & 12 & 1.35 \\
\hline Bronchodilators & 11 & 1.24 \\
Antispasmodics & 10 & 1.12 \\
Others & 72 & 8.12 \\
\hline
\end{tabular}




\section{DISCUSSION}

The different prescribing indicators and the distribution of different categories of drugs in the prescriptions analyzed in this study provided an insight into the prescribing behavior of the physicians in a tertiary care hospital in Nepal.

Average numbers of drugs per prescription in this study were 4.34. When the patient is critically ill and diagnosis is not confirmed at the time of admission to the tertiary care hospital, empirical polypharmacy may be required. But it is always preferable to keep the mean number of drugs per prescription as low as possible to reduce the cost of treatment and to minimize the adverse effects \& drug interactions.

Use of generic names in prescription eliminate the chance of duplication of drug products and also reduce the cost of the patient. ${ }^{11}$ Only $2 \%$ of the drugs were preseribed by the generic names in a study from Allahabad, India ${ }^{12}$ and from JIPMER, Punditry, India it was $43.9 \%{ }^{13}$. Das BP et al described in their study that none of the non-steroidal anti-inflammatory drugs was prescribed by generic name in orthopedic department of B.P. Koirala Institute of Health Sciences, Nepa ${ }^{14}$.A discussion with the clinicians revealed that they preferred to write brand names of drugs of repute rather than by generic names, since it may result in purchase of drugs of uncertain bioavailability.

The percentage of prescriptions containing antimicrobial (s) were high $(72.05 \%)$ in our study in comparison with studies conducted in other countries as reported by WHO. ${ }^{8}$ The common causes of morbidity in Nepal are gastrointestinal and respiratory tract infections like enteric fever and tuberculosis and also malnutrition. ${ }^{15}$ Probably this could be the reason for high incidence of use of antimicrobials in hospitalized patientsin our study. Still, considering the cost effectiveness and serious problems of development of resistance, their indiscriminate use should be restricted.

In our present study, the percentage of prescriptions containing injections were $66.6 \%$ which was almost similar to data from Manipal Teaching Hospital, Pokhara $(54.52 \%)^{16}$, considering the fact that most of the hospitalized patients in a tertiary care hospital are critically ill and most of the time require parenteral therapy. But the data was much higher than that in Srilanka, where only $1 \%$ of the prescribed drugs in outpatient department were injectable. ${ }^{17}$ Apart from the high cost of parenteral therapy, the other different disadvantages of such therapy should also be considered. Of special importance, with the increasing rate of HIV positive cases of Nepal, the potential therapy should be further restricted. ${ }^{18}$
In our study, the percentage of drugs from essential drug lists of WHO and Nepal were $41.76 \%$ \& $38.20 \%$ respectively. The use of fixed-chose drug combinations was $17.49 \%$ which is lower than the study conducted by Victor CG et al (30\%) in Brazil in $1982 .{ }^{19}$ There were only $20 \%$ and $6.40 \%$ of fixed drug combinations that were prescribed from the essential drug lists of WHO \& Nepal respectively. Use of drugs from the essential drug list should be promoted for optimal use of limited financial resources, to have acceptable safety and to satisfy the health needs of the majority of the population. ${ }^{20}$

The must commonly used group drugs in this study were antimicrobials (32.27\%) followed by analgesics $(11.85 \%)$ and drugs for acid-peptic disorders (10.72\%) and these findings are almost similar to the findings of the study of JIPMER, Pondicherry, India. ${ }^{13}$

\section{CONCLUSION}

Irrational use of drugs is a common occurrence throughout the world..$^{21}$ There were fewer number of drugs per prescription, fewer fixed drug combinations, more drugs from essential drug list and frequent generic prescriptions in our study as compared to other studies. ${ }^{12,14,16}$ Still, it is preferable to keep the mean number of drugs per prescription as low as possible, since higher figures always lead to an increased risk of drug interactions, affect patients' compliance, and increase hospitalpatient costs. Further, prescribing drugs more in generic names may help in cheaper treatment. Irrational prescribing can be avoided by sticking to the ideal prescription writing ${ }^{22,23}$ following the p-drug and p-treatment concept, ${ }^{24}$ and by consulting the WHO and National essential drugs lists. This initial audit report is to give feedback to the prescribers and such periodical audit of drug prescribing is required to rationalize the prescribing practices.

\section{REFERENCES}

1. Worl d Heal th Organi zati on. The rati onal use of drugs: Report of the conf er ence of experts. Nai robi and Cener a:WHQ 1995.

2. Seth SD(edi tor). VHDGi de to Cood Prescri bi ng. The Textbook of Phar nacol ogy. $2^{\text {nd }}$ ed. NewDel hi : Churchi I I ñLi vi ngstone; 1999. $788-91$

3. Kar nacharyaPCI nProceedi ngs of probl enori ent edt rai ni ng on Rat i onal Therapeuti cs. TU, I OM Med Edu Dept., Kat hrandu;1992.

4. Uppal R, Nayak P, Sharns PL. Preseri bi ngt rends i ni nternal nedi ci ne. I nt Q i n Phar mTher Toxi col 1984; 22:373- 76.

5. Kri shnaswany $K$, Di nesh $K B$, Radhai ah $G$ A drug survey ñ precepts and practi ces. Eur J O i n Phar nacol 1995; 29:36370. 
6. Pradhan SC, Shevade DG Shashi ndran OH Bapna J S. Drug ut i I i zati on studi es. Nati onal MedJ I nd P88; 185- 89.

7. Kathmandu Uhi versi ty. DuugLsel ndi cat or Study (Prescri pti on Audi t). Kat hnandu: Kathnandu Uhi versi ty curri cul um, 2001 150- 52.

8. Worl d Heal th Organi zati on. Howto i nvesti gate drug use in heal th $\mathrm{f}$ aci I $\mathrm{i}$ ti es:Sel ect ed dr ug use i ndi cat or s. Geneva: WHO; 1993;1:1- 87.

9. Worl d Heal th Organi zati on. WHODrug i nf or nati on. Ceneva: WHO; 2002; 16: 139- 54.

10. Department of Drug Adnini strati on : H s Maj esty's Governnent, Nepal . Nati onal Li st of Essenti al Drugs. Nepal : HMG; 2002.

11. Benet LZPri nci pl es of prescri pti on order wi ti ng \&pati ent conpl $i$ ancei instructi ons. I n: HardmanJ GLi nbardLE,Nol i nof $f$ PB,Ruddon RMG I man AG (edi tors). Goodman \& G I man's the phar nacol ogi cal basi s of Ther apeuti $\mathrm{cs}, 9^{\mathrm{th}}$ ed. NewYork: MtGraw H I I ; 1996. 1697- 706.

12. Ansari KU, Si ngh S, Pandey RC. Eval uati on of prescri bi ng pattern of doctors for rati onal drugtherapy.I nd anJ Pharnacd 1998; 30:43- 6.

13. Shevade DG Pradhan SC Audi ti ng of prescri pti ons in a gover ment teachi nghospi tal andf our retai I ned cal stores i n Pondi cher ry. I ndi an J Phar nacol 1998; 30:408- D.

14. Das BP, Adi kari N Garg M Rauni ar GP, Naga Ranm MA Uti l i zti onpattern of NSA BSi northopedi cpracti ceat aterti ary care hospi tal in Eastern Nepal . J Nep Ned Assoc 2000; 39:315- 18.
15. H s Mij estys Covernent of Nepal , M ni stry of heal th, Pol i cy, $\mathrm{Pl}$ anni ng, Moni tori ng and supervi si on D vi si on. Heal th I nf or nati on Bul I eti n. Kat hnandu: HMG $992 ; 4: 7$.

16. Sarkar C, Das B. Prescri bi ngtrends i na Teachi ng Hbspi tal in Western Nepal. J NGMC 2002;2: 4- 7.

17. Tonson GAngunauel a I . Pati ents, doctors and thei $r$ drugs ñ Astudy at four l evel s of heal thcarei nanarea of Sril anka.Eur J C in phar nacol 1990; 39(5): 463-67.

18. Anonynous. H V/A DS and Sexual I y transnitt ted di seasesRegi onal Report- P96. Regi onal of fi ce of South-East Asi a: WHO 1996; 24- 5.

19. U ctor GGFacchi ni LAFi I ho Ny. Dugusei nBrazi I i anHbspi tal s. Trop Doct 1982; D:231 35.

20. Worl d Haal th Organi zati on. The sel ecti on of essenti al drugs, Techni cal report seri es no-65, Report of a VHO expert conmit tee. Geneva; WHO 1977.

21. Souner ai SB. Fact ors i nf I uenci ng prescri bi ng.Aust J Hbsp Pharm 1988 (suppl); 18:9- 16.

22. Puthaval a AK, Mansuri SMPharnacy practi cal $s$ for nedi cal st udents. $2^{\text {id }}$ ed. Ahnædabad; 1986; B- 15.

23. Budhi raj a RD Mannual of Practical Pharmacy. $2^{\text {d }}$ ed. Bonbay:Popul ar Prakashan; 1993;6.

24. de Vri es TPGM Henni ng RH Hbger zei I HV, Fresl e DA Gui de to good Prescri bi ng: a practi cal nanual .Ceneva, Vorl d Heal th Organi zati on, Acti on Progr anme on Essenti al Drugs; 1995; 14- 31

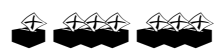

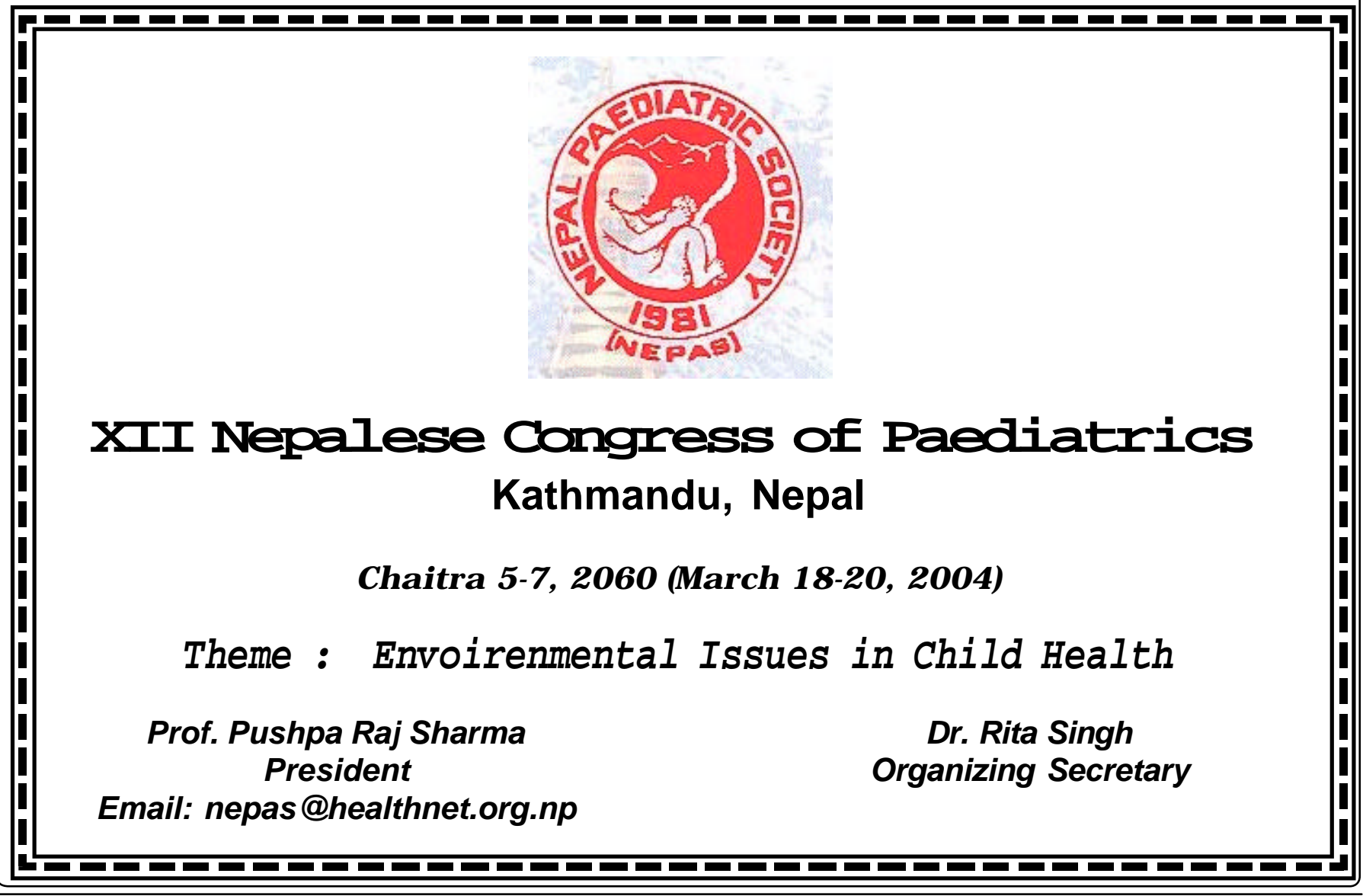

